\title{
Aspectos da formação feminina no romance $A$ Muralha de Dinah Silveira de Queiroz
}

Maria Braga Barbosa 1

\begin{abstract}
RESUMO: O romance A Muralha de Dinah Silveira de Queiroz pode ser lido como um romance de formação (Bildungsroman) feminino, embora algumas transgressões sejam feitas ao gênero, já que se trata de uma narrativa que se passa no início da era colonial brasileira. A partir desta leitura é possivel deparar com um narrador que volta os olhos sobre a condição da mulher europeia imersa no perigoso, longinquo e assustador mundo da colônia.

ABSTRACT: The novel The Wall of Dinah Silveira de Queiroz can be read like a novel training (Bildungsroman) female, although some transgressions are made to the genre, since it is a narrative that is happening at the beginning of the Brazilian colonial era. From this reading is possible to encounter a narrator who turns his eyes on the condition of European woman, distant immersed in the distant dangerous and scary world of the colony.
\end{abstract}

PALAVRAS-CHAVE: Bildungsroman; Colonialismo; Mulher; Transgressão; Impossibilidade.

KEYWORDS: Bildungsroman; Colonialism; Woman; Transgression; impossibility.

\section{Introdução}

A tradição do romance de formação (Bildungsroman) se consolida dentro de um tempo e espaço específicos na Europa moderna. Trata-se da ficção literária realista produzida e consumida pela classe burguesa alemã no período do seu advento. Estudiosos do gênero, embora longe de um consenso, admitem certas características mais ou menos regulares neste tipo de obra literária que permitem reconhecer um paradigma. Um modelo de Bildungsroman, ou romance de formação,

1 Mestranda em Literatura dentro da linha de pesquisa Crítica Literária, pela Universidade de Brasília; professora de Língua Portuguesa-Literatura do Instituto Federal de Brasilia. 
geralmente apresenta entre seus elementos um protagonista jovem burguês que se separa da casa paterna; uma viagem que lhe proporciona descobertas; o envolvimento com tutores mais velhos (conhecedores do mundo); experiências amorosas; casamento; consciência sobre seu aprendizado; morte ou não. A recorrência, aceitação e consolidação do gênero torna-o uma eficaz ferramenta de educação na classe onde e para a qual surgiu. Assim, a experiência do herói no curso de sua formação ensinava o jovem leitor sobre os seus próprios possiveis enfrentamentos.

O avanço deste tipo de romance por lugares e tempos distantes daqueles de sua origem não ocorre sem a ampla transgressão do conceito inicial de Bildungsroman. A tradição do romance de formação abriu mão de uma série de elementos estruturais deste gênero, na medida em que outros territórios e outros povos entravam para o enredo.

O mundo colonial constituiu um ambiente rico e propicio para criação ficcional do romance. Nenhuma experiência no velho mundo teria um peso tão atrativo e fantástico quanto as vividas além mar. Para tanto contribuem os novos povos e a nova natureza encontrados na colônia, ininteligiveis, resguardando sedução e perigo. O desafio de seu desbravamento chamava toda espécie de aventureiro e oferecia uma grande narrativa. É o caso da multiplicação dos romances de aventuras e de viagens como Robinson Crusoé (1719) de Delfoe, Viagens de Guliver (1726) de Swift, Moby Dick (1851) de Melville, entre tantos que ganharam notoriedade nos séculos que seguiram às grandes conquistas marítimas. Wilma Patrícia Maas registra em $O$ cânone mínimo a relação entre o romance de formação e as histórias de aventura e de viagens. No Bildungsroman, o aprendizado do protagonista é parte central de sua estrutura. No mundo da colônia - cenário preferido dos escritores de aventuras e de viagens - as descobertas são intensas e intermitentes.

O romance A Muralha de Dinah Silveira de Queiroz, publicado em 1954, conta a tomada de consciência desse novo mundo por parte de uma de uma personagem feminina. A jovem Cristina, de abastada 
família tradicional portuguesa, que chega à colônia trazida pela promessa de casamento com um bandeirante herdeiro de terras, desembarca cheia de sonhos e projetos para a nova vida na nova terra. Trata-se da formação de uma mulher em condições adversas à moral da época, dentro da selva colonial, longe da matriz cultural européia, das pompas sociais, das convenções religiosas, temendo um processo de animalização e lutando para não perder o senso de civilidade.

Dentro de uma ampla conceituação sobre o gênero Bildungsroman, Maas refere-se às vivências de erros, enganos $\mathrm{e}$ decepções do protagonista que busca o equilíbrio com o mundo. A Muralha segue essa trajetória e apresenta elementos de romance de formação feminino que são apontados por Cíntia Schwantes, tais como a presença de uma mãe interditada como modelo, a educação informal da protagonista, a ligação da mulher com a natureza, uma experiência amorosa mal sucedida e momentos de epifania.

\section{A chegada à nova terra}

A colônia é o ambiente ideal para narrativa realista do maravilhoso. Nesta terra é possivel encontrar um animal que fala (o papagaio); uma vastidão de florestas sem dono; seres de costumes bizarros - o outro se revelando com toda força, deixando dúvidas quanto a serem humanos ou não. Ali naquela terra, ironicamente, a protagonista de A Muralha encontra até mesmo uma mulher que escreve poemas e lê Camões. O novo mundo se revela para Cristina como um outro nascimento, tamanha lhe parece a estranheza daqueles ares. A idéia de nascimento para a moça é positiva, embora alguém, ao nascer, esteja entrando na incerteza completam, assim como acontece na chegada à colônia.

Logo no momento do desembarque, surge a voz de advertência daquele que seria o primeiro tutor de Cristina, o Capitão-Mor do navio, experiente e conhecedor da nova realidade. "Cure-se a menina das 
ilusões (...) Vede bem esta miséria. De perto é ainda pior! Porque este povo cheira diferente" (A Muralha, Nova Fronteria, p.12). O capitão alerta a moça sobre a selvageria da colônia, sobre a submissão das mulheres, a indecência e o desconforto da vida naquele lugar.

Cristina era jovem chegando a uma terra também jovem, a "terra moça", como chamam seus moradores, tão nova que ainda não possui nome certo. No processo de descoberta da protagonista ela entenderá que todos os adjetivos desejáveis atribuídos àquela terra eram fantasiosos, frutos do enlouquecimento que esse mundo causava aos seus invasores. Entretanto, o mais grave de tudo é descobrir como o vício humano se sustenta em qualquer condição de existência, sobretudo para quem já conhece a ganância e o valor do ouro. Seria esta cobiça a causadora da indiferença de seu noivo. Tiago deveria preferir a vida errante na bandeira, dormindo com as índias em busca das minas de ouro a tê-la como esposa dedicada.

Os homens que chegavam à terra se contaminavam com a vida selvagem, esquecendo os principios e a moral da sociedade portuguesa, no vício da libertinagem sexual com escravas e índias. Mesmo os patriarcas cristãos e idôneos entregavam-se à devassidão do sexo com as nativas, povoando a colônia com seres mestiços, bastardos sem sangue, que não podiam receber o nome de suas linhagens, manchados e entregues à sorte da servidão. Como escreveu Paulo Prado no seu texto veemente de protesto contra a embriaguês sexual e a euforia da ganância pelo ouro que dominou os primeiros colonos do Brasil:

Entregavam-se com a violência dos tempos à saciedade das paixões de suas almas rudes. Uma delas foi a lascivia do branco solto no paraíso da terra estranha. Tudo favorecia a exaltação do seu prazer: os impulsos da raça, a malícia do ambiente físico, a continua primavera, a ligeireza do vestuário, a cumplicidade do deserto e, sobretudo, a submissão fácil e admirativa da mulher indígena, mais sensual do que o homem como em todos os povos primitivos, e que em seus amores dava preferência ao europeu, talvez por considerações priápicas, insinua o severo Varnhagen. Procurava e importunava os brancos nas redes em que dormiam, escrevia Anchieta. Era uma simples máquina de gozo e 
trabalho no agreste gineceu colonial (PRADO, 2002, p. 43).

Além da debilidade moral, os homens da colônia estavam expostos a horrores de toda sorte; à imensa mortalidade no sertão, quer pelas moléstias da selva, pelos animais, por índios ou acidentes com o desbravamento. Mas todo sofrimento não era o suficiente para livrá-los da hipnose pelas aventuras e pelo ouro, como observa Mãe Cândida em conversa com a nora Cristina: "O sertão, às vezes, é pior que a guerra, que a peste. É uma espécie de febre que dá nos homens. Saem do conforto das casas para passar fome, sofrer os riscos, às vezes sem nenhuma vantagem" (A Muralha, Nova Fronteira, p. 196). A mata selvagem e feiticeira não apenas atraía como encantava alguns desses homens. A terra mística tinha desenvolvido em Tiago o dom de ler mapas e o futuro nas estrelas, da mesma forma que os homens nativos sabiam a arte da sobrevivência naquelas selvas.

\section{A situação da mulher}

O destino reservado às mulheres, por outro lado, não tem o brilho do heroísmo e da descoberta de tesouros como acontece com o bandeirante. É uma sina enfadonha, solitária e muito áspera. O corpo de mentores da protagonista são as mulheres da fazenda. Com angústia, Cristina aprende e participa da sua persistência na solidão à espera dos homens afundados no sertão, sem promessas de retorno, mas que eventualmente reaparecem para descansar da selva, demarcar o território nas fazendas e famílias, sempre ansiosos pelo retorno à bandeira e às aventuras. São as mulheres quem lidam com o plantio e com o gado, de mãos grosseiras, de pele queimada pelo sol. São elas quem guardam a propriedade de invasores, pegando em armas quando preciso, se revestindo de coragem masculina. Não se esquecendo da importância de suas linhagens, resguardam a honra dos maridos e a própria, criando os filhos mestiços de seus homens, calando sobre o assunto da traição, fingindo não ser válido o adultério em se tratando 
de mulheres negras e índias. "O mundo sempre foi e continua a ser dos homens"( A Muralha, Nova Fronteria, p. 211), observa a personagem cosciente da submissão que lhe é reservada.

O estudo de Cintia Schwantes contempla a questão da mulher e sua relação com a natureza. Historicamente, o homem (da sociedade patriarcal) têm enxergado na mulher, assim como na natureza, o "outro" que deve ser sempre dominado, pois, ainda que sedutor e compassivo, não pode ser totalmente compreendido, tornando-se perigoso. Em A Muralha, mulher e natureza estão lado a lado, todavia, como inimigas. Este embate se deve ao fato de ser a mulher da colônia quem preserva com mais cuidado a civilidade, a cultura e os valores da sociedade europeia.

A prima Isabel aparece como uma possibilidade assustadora do que pode vir acontecer com uma mulher naquelas circunstâncias. Grotesca e masculinizada, Isabel é experimentada nos sertões, nas armas. Perdeu suas qualidades femininas, sua honra de mulher branca e vive isolada da casa, num processo de animalização, assim como os homens. Sua mascote é Morena, uma jaguatirica que cria desde filhote, a única companhia possivel para ela. Assim como o animal, Isabel é perigosa, traiçoeira, capaz de parir solitária e depois abandonar o filho. "Era curiosa aquela identificação. Cristina pensava, reparando nas feições inchadas de Isabel, no seu rosto manchado, nos olhos mais claros que a face: Elas até estão ficando parecidas.” (A Muralha, Nova Fronteria, p. 196).

Dessa forma, Cristina compreende que para uma mulher subsistir na selva colonial, é necessário também lutar pela razão. A decadência, no entanto, parece inevitável. Esta decadência cerca o patriarca Dom Brás, o líder da bandeira, dono de muitas terras e escravos, tio e sogro da moça. Sua família entra aos poucos numa perdição progressiva, começando pela descoberta da gravidez da sobrinha Isabel. Em seguida, Rosália, a filha caçula, foge da fazenda com o inimigo e futuro assassino de seu pai. Basília, a filha mais velha, tem o rosto deformado no combate com os indios, ficando-lhe 
impossível qualquer sorte de felicidade conjugal. A perdição se segue nos membros da família até que reste (ferido de guerra) apenas Tiago, o principe da bandeira, esposo de Cristina.

Ao iniciar uma resistência e impor o desejo de recuar, voltar para o reino, desistir daquele casamento, fugir de sua própria perdição enquanto mulher e humana, Cristina depara com a arrogância e altivez do sogro e sogra, que lhe jogam em rosto o quanto esta atitude poderá bani-la do ambiente familiar e de um convívio social digno. Mesmo reconhecendo esse risco, Cristina entende que a vida das mulheres errantes, como as meretrizes de Portugal, ainda pode ser mais razoável do que a possibilidade de vida que encontra nas clareiras da selva colonial. Schwantes aponta como recorrente no romance de formação feminino o surgimento da protagonista rebelde que se arrisca a ser excluída da sociedade ao enfrentar uma condição opressora.

Em primeiro lugar, como a Bildung da protagonista feminina se faz em condições adversas, a própria narrativa perde a neutralidade para tornar-se engajada (vide o final irado de Middlemarch) e em segundo lugar, e como decorrência do mesmo fato, surgirá a protagonista rebelde, não-convencional, disposta a empurrar os limites dos papéis sociais à sua disposição. Esse processo, que normalmente inclui a necessidade de liberar-se dos efeitos de uma educação restritiva, irá se prolongar significativamente em muitos Bildungsromane femininos. Embora o protagonista masculino também se rebele contra os ditames de sua sociedade, ele tem as alternativas de encontrar outro espaço social aberto para ele ou de ampliar os espaços em seu próprio grupo de origem; em ambos os casos, sua reinserção social é muito mais fácil que a de sua contraparte feminina. Ela, de fato, arrisca ser excluída permanentemente quando questiona os limites que lhe são impostos com base em seu gênero (SCHWANTES, 1998, p. 37).

Como tradição no romance de formação feminino, a protagonista não vive uma experiência amorosa bem sucedida. Quando Tiago finalmente resolve revelar-lhe o amor que sente, esquecendo seus anseios e orgulho, Cristina já não é mais capaz de recebê-lo. Está transformada numa fortaleza fria e altiva, determinada a abandonar a 
terra odiada e tentar recuperar as origens. A impossibilidade desse retorno, no entanto, não é apenas físico. Ela não pode nem transpor o mar de volta e nem recuperar a doçura de antes. Aos poucos, a moça orgulhosa e sonhadora da metrópole vai se despindo dos seus mimos e orgulhos fúteis ao se defrontar com a necessidade de sobrevivência. A terra a transformara naquela nova criatura forte o suficiente para escapar com razão, compreendendo a crueldade e indiferença da natureza, compreendendo "como a terra era muito mais forte que a vontade humana"(A Muralha, p. 278).

\section{O aprendizado}

Bakhtin destaca como diferencial no romance de formação a construção de um herói mutável, capaz de surgir em grau zero de personalidade para depois criar uma imagem crescente dentro do romance. Não crescente no sentido de um aprimoramento profissional, moral ou finaceiro, mas crescente porque sofre mudanças que o capacitam para enfrentar ou mesmo suportar as condições do meio no qual se encontra.

Ao lado desse tipo predominante e muito difundido, há outro tipo de romance, muito mais raro, que apresenta a imagem do homem em devir. A imagem do herói já não é uma unidade estática, mas, pelo contrário, uma unidade dinâmica. Nesta fórmula de romance, o herói e seu caráter se tornam uma grandeza variável. As mudanças porque passa o herói adquirem importância para o enredo romanesco que será, por conseguinte, repensado e reestruturado. O tempo se introduz no interior do homem, impregna-lhe toda a imagem, modificando a importância substancial de seu destino e de sua vida. Pode-se chamar este tipo de romance, numa acepção muito ampla, de romance de formação do homem (BAKHTIN, 1992, p.237).

Essas mudanças pelas quais passa o herói são condicionadas pelo seu aprendizado ao longo do enredo. Fazem parte desse processo a 
renúncia de ambições, paixões e entusiasmos, a tentativa e o erro, seguindo orientação de terceiros e a consciência do processo de transformação. O aprendizado da protagonista Cristina é todo dentro de uma educação informal intensa, na medida em que é plena a sua imersão naquele mundo de "maravilhas e assombramentos". Nesta terra alienígena o abandono pode ser completo, as mulheres são "feitas de uma outra massa", como observa Cristina, na tentativa de compreender esse outro mundo e essa outro humano. Acreditando que poderá resistir ao embuste do lugar pagão e insano, passando a odiar a nova terra, Cristina guarda uma outra esperança: a do retorno.

Maas aponta em O Cânone mínimo o erro e a decepção como essenciais à trajetória do protagonista no romance de formação. Esse protagonista, já separado da casa paterna ou de seu ambiente de origem, deve ter a consciência de que suas aventuras levam-no pelo processo de autodescobrimento e de orientação no mundo. É exatamente neste campo que entra Cristina, em meio à leva de homens e mulheres que deixaram as terras da Europa e se afundaram no desconhecido mundo da colônia, sem garantias, mas com promessas de um paraíso. É assim que as descobertas da moça vão sendo feitas uma a uma sob seguidos desapontamentos que, de início, são apenas tristes para depois tornarem-se traumáticos.

A primeira decepção de Cristina é encontrar, não o noivo a sua espera, e sim um escravo índio, Aimbé, que será seu segundo tutor, aquele que lhe apresentará a terra mais detalhadamente enquanto ela segue se espantando pela trilha da mata que conduz à Piratininga. A partir de então uma sucessão de decepções vão se fazendo. Primeiro a perda da arca de presentes destinados à família do noivo, uma riqueza de peças do reino que cai no abismo da selva tornando-se irrecuperável. Depois o constatar que a vila de Piratininga não é menos miserável que o porto de São Vicente, assim como a casa do noivo, sem luxos, repleta da simplicidade rústica e selvagem do lugar. E em seguida uma decepção pior: a indiferença do noivo Thiago. Mas a auge do aprendizado de Cristina acontece quando ela entende que não é mais 
possivel voltar. Ao final do romance, depois de luta e caminhada exaustiva, ela compreende num momento epifânico, a impossibilidade do retorno à antiga terra e à antiga vida, a impossibilidade de encontrar o seu lugar na sociedade, a condenação ao confinamento como mulher reprodutora, guardiã dos lares miseráveis, da honra dos maridos, na melancolia das terras desertas de razão.

A rudeza das circunstâncias locais agem sobre a protagonista transformando-a de moça ingênua e sonhadora em mulher corajosa e audaz, assim como suas tutoras. A atuação de Cristina é determinante para a descoberta dos jogos de interesse locais, e para a sobrevivência do marido, perpetuador da luta de Dom Brás pela posse das minas de ouro. "Cristina sentia que a sua determinação lhe dava uma certa altivez, que a segurança que sempre havia almejado lhe chegara, enfim, ao coração. Como aprendera a ser alguém dentro da Lagoa Serena" $A$ Muralha, Nova Fronteria, p. 275).

\section{Conclusão}

Bakhtin chama atenção para um tipo de romance de formação que seria, segundo ele, o mais importante entre os quais classifica. Trata-se de um modelo em que a evolução do homem se processa ao lado da evolução histórica. Ao passo em que, nos outros tipos de romance, o tempo e a história são pano de fundo estável e imóvel, neste caso específico, no romance realista, a formação histórica do mundo passa a se refletir no próprio homem, sua formação já não é mais um "dado particular".

O homem já não se situa no interior de uma época, mas na fronteira de duas épocas, no ponto de passagem de uma época para a outra. Essa passagem efetua-se nele e através dele. Ele é obrigado a tornar-se um novo tipo de homem, ainda inédito. É precisamente a formação do novo homem que está em questão. A forma organizadora do futuro desempenha portanto um importante papel, na mesma medida em que o futuro não é relativo à biografia privada, mas concernente ao futuro histórico (BAKHTIN, 
1992, p. 240).

Como romance de formação feminina, A Muralha retoma a condição da mulher num momento muito peculiar de uma sociedade patriarcal: a condição do desbravamento da colônia. A bravura e liderança de certas mulheres ainda não seriam suficientes para impelilas a um papel social menos subalterno, mas são atitudes reveladoras da competência e potencialidade feminina. Sob dadas condições históricas extraordinárias, quando tornam-se ineficazes certas condutas sociais, antigas tradições encontram o momento certo para suas rupturas. A narrativa revela como as conquistas das mulheres poderiam ser muito mais antigas. $O$ que aconteceu a Cristina, seu aprendizado e transformação estão marcados pelo processo mais violento da história do mundo: a colonização.

A impossibilidade de retorno à pátria, que foi a maior descoberta da protagonista é também a impossibilidade do retorno para um mundo que tentasse recomeçar uma outra história, onde o tráfego febril dos mares e a barbárie entre os povos pudesse ser amena. Pessimismo e angústia, como lembra Schwantes, "irão permear boa parte da reflexão teórica sobre o romance de formação feminino". (SCHWANTES, 1998, p. 26.) Os desapontamentos e a melancolia são crescentes na obra. A Muralha é válido como romance de formação feminino porque tenta reconstruir o papel da mulher, revelando sua identidade num momento histórico que sempre foi espaço para condecorações e homenagens aos feitos de grandes homens.

\section{Referências bibliográficas}

BAKHTIN, Mikhail, O romance de educação na história do realismo - In: Estética da Criação verbal- Trad: Maria Ermantina Galvão Gomes Pereira. São Paulo: Livraria Martins Fontes Editora, 1992.

MAAS, Wilma Patrícia, O Cânome Mínimo - O Bildungsroman na história 
da literatura. São Paulo: Editora UNESP, 2000.

PRADO, Paulo, Retrato do Brasil- In: Salviano Santiago (Org.). Intérpretes do Brasil vol. 2. Rio de Janeiro: Editora Nova Aguilar, 2002.

QUEIROZ, Dinah Silveira de, A Muralha - Rio De Janeiro. Editora Nova Fronteira, $7^{\mathrm{a}}$ edição, sem ano de publicação.

SCHWANTES, Cíntia, Interferindo no Cânone: a questão do "Bildungsroman" feminino com elelmentos góticos. Tese de doutoramento em Letras. Ano de obtenção: 1998. Universidade Federal do Rio Grande do Sul, UFRGS, Brasil. 